\title{
The Effect of High Dose Antenatal Vitamin E on Hypoxia-Induced Changes in Newborn Rats
}

\author{
ÇIĞDEM INAN, ILKNUR KILIÇ, KAMER KILINÇ, ÖMER KALAYCI, AND ESIN KOTILOĞLU \\ Departments of Pediatrics [C.I.I., I.K., Ö.K.], Biochemistry [K.K.], and Pediatrics, Division of Pediatric \\ Pathology [E.K.]
}

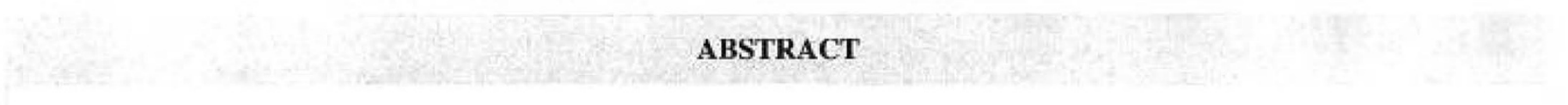

The protective effects of high dose antenatal vitamin $\mathrm{E}$ on hypoxemia in newborn rats were investigated. The subjects were 1-d-old Wistar rats weighing 5-6 g which were born to mothers weighing $245-250 \mathrm{~g}$. Three groups of rat pups, each consisting of eight newborn rats, were used: nontreated control group, hypoxic group, and vitamin $\mathrm{E}$ group. The mothers of pups in the last group were given vitamin E $(2000 \mathrm{mg} / \mathrm{kg} / \mathrm{d})$ antenatally on 3 consecutive days. Hypoxia was induced by breathing of a mixture of $8 \%$ oxygen and $92 \%$ nitrogen for $3 \mathrm{~h}$. Then pups were allowed to inhale normal atmospheric air for $30 \mathrm{~min}$. All rats were killed on the first day of life after the procedure of hypoxia and reoxygenation. The brains, lungs, livers, intestines, and kidneys were studied biochemically and histopathologically. The hypoxia-induced biochemical changes were determined by measuring lipid peroxidation and myeloperoxidase activity. Vitamin E effectively inhibited hypoxia-induced lipid peroxidation in liver and intestines, and decreased the levels of thiobarbituric

Hypoxia and ischemia are major problems in the neonate despite advanced antenatal and neonatal care. No specific treatment has been shown to improve the high morbidity and mortality associated with this problem.

Among many factors that adversely effect the function of placenta in the gas exchange between the fetus and the mother are maternal hypoperfusion induced by anesthesia, uterine hypertonicity, abruptio placenta, and obstruction of the umbilical cord. Any episode of fetal hypoperfusion can cause mild or severe fetal hypoxemia (1). After the reintroduction of oxygen, large amounts of oxygen-free radicals are produced. These radicals can initiate lipid peroxidation and attack other biologic targets (2-4).

Low levels of oxygen radicals produced under physiologic conditions are effectively removed or scavenged by enzymatic and nonenzymatic antioxidant systems of the body $(5,6)$. However, under several pathologic conditions these antioxidant mechanisms may be overwhelmed by radicals produced in excessive amounts.

Received June 6, 1994; accepled April 13, 1995.

Correspondence: Çiğdem İnan, M.D., Nazilli sokak 2/11, 06540 A. Ayrancı, Ankara, Turkey. acid-reactive substances in brain. In agreement with lipid peroxidation, tissue associated myeloperoxidase activity was increased in liver, intestines, and kidneys, but not in brain and lungs, of the hypoxic group. Histopathologic changes in intestines were epithelial separation and submucosal polymorphonuclear leukocyte infiltration. In the liver, leukocyte infiltration was observed only near the portal areas. These changes were not observed in the vitamin E group. It was concluded that high doses of antenatal vitamin $\mathrm{E}$ may protect the newborn rat pups against hypoxia-induced tissue injury. (Pediatr Res 38: 685-689, 1995)

\author{
Abbreviations \\ MPO, myeloperoxidase \\ TBARS, thiobarbituric acid-reacting substances \\ MDA, malondialdehyde \\ $\mathbf{H} \& \mathbf{E}$, hematoxylin and eosin
}

Vitamin E ( $\alpha$-tocopherol) is one of the most important nonenzymatic antioxidant (5). One of the primary function of this vitamin is to protect cell membranes against oxidant stress by inhibiting lipid peroxidation (7-9). However, the vitamin E level in premature and low birth weight babies is low (10), and it is reported that the passage of vitamin $\mathrm{E}$ through the placenta is limited. Administration of vitamin $E$ to newborn babies should provide a protective antioxidant effect $(10-13)$. In this study we investigated the possible protective effects of antenatal vitamin $E$ administration on hypoxia in newborn rats.

\section{METHODS}

Animal model. The subjects of this study were 1-d-old Wistar rats weighing 5-6 g which were born to healthy and well nourished mothers of 245-250 g. The newborns were divided into three groups each consisting of eight rats. The first group served as the nontreated controls. The second group was subjected to hypoxic insult on the first day of life. The third group received vitamin $\mathrm{E}$ antenatally and was subjected to hypoxic insult. Vitamin E treatment consisted of tocopherol acetate (Ephynal ${ }^{\circ}$, Roche) given at $2000 \mathrm{mg} / \mathrm{kg} / \mathrm{d}$ intramuscularly for $3 \mathrm{~d}$ from the 16 th to 18 th $\mathrm{d}$ of pregnancy. 


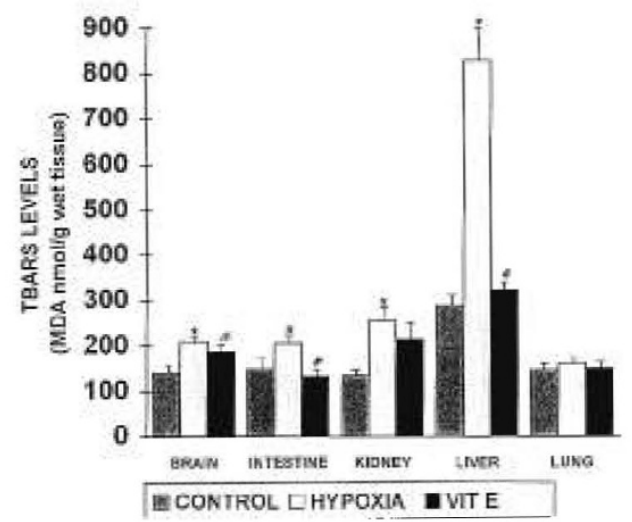

Figure 1. The levels of TBARS (lipid peroxidation) in rat pups tissues. Values are means $\pm 1 \mathrm{SD} .{ }^{*} p<0.05$ for lipid peroxidation compared with control group and $\# p<0.05$ for protection by vitamin $\mathrm{E}$ compared with hypoxic group.

Immediately after birth, the newborn rats were placed in 500-mL airtight jars, and hypoxia was induced by breathing of a mixture of $92 \%$ nitrogen and $8 \%$ oxygen for $3 \mathrm{~h}$. The jars were partially submerged in a water bath thermostatically regulated at $37^{\circ} \mathrm{C}$. After the hypoxic period, the rats were transferred to another jar at $37^{\circ} \mathrm{C}$ where they were allowed to inhale normal atmospheric air for $30 \mathrm{~min}(14,15)$.

Rats were immediately decapitated at the end of the reoxygenation period, and the tissues (brains, lungs, kidneys, livers, and intestines) were immediately removed for biochemical and histopathologic studies.

Tissue samples were preserved in $10 \%$ buffered formalin for histopathologic investigation. After the routine dehydration process, 5- $\mu \mathrm{m}$ sections were stained with H\&E. The pathologic review by light microscopy was carried out by a pathologist using experimental double blind conditions. The specimens for biochemical studies were frozen at $-70^{\circ} \mathrm{C}$.

Determination of TBARS. Tissues which had been frozen at $-70^{\circ} \mathrm{C}$ were immediately weighed and homogenized in 10 volumes of ice-cold phosphate buffer $(50 \mathrm{mM}, \mathrm{pH} 7.4)$ using a glass-glass homogenizer. Determination of lipid peroxidation and myeloperoxidase activity was carried out on this homogenate.

Lipid peroxidation in tissues was determined using the method of Uchiyama and Mihara (16). Tetramethoxypropane was used as the standard and the level of TBARS was calculated as nanomoles of MDA per gram of wet tissue.

Determination of myeloperoxidase activity. Tissue-associated MPO activity was measured as described by Grisham et al. (17). One unit of enzyme activity was defined as the amount of enzyme that produced a change in absorbance per minute of 1.0 at $37^{\circ} \mathrm{C}$ in the final volume of assay procedure.

Statistics. Values are mean $\pm \mathrm{SD}$. The Mann-Whitney $U$ test was used for statistical analysis. A $p<0.05$ value was considered to represent a significant difference between the compared values.

\section{RESULTS}

Biochemical results. In the hypoxic model lipid peroxidation (measured as TBARS or MDA) was stimulated in all tissues studied except the lungs. Mean lipid peroxide levels in the livers of the control, hypoxic, and vitamin $\mathrm{E}$ groups were $286.8 \pm 21,4,828.0 \pm 72.0$, and $321.0 \pm 15.4 \mathrm{nmol} / \mathrm{g}$ of wet weight, respectively; in intestinal tissues the MDA levels were $148.8 \pm 22.4,204.6 \pm 18.2$, and $132.7 \pm 15.4$, respectively. Vitamin E effectively inhibited hypoxia-induced lipid peroxidation in these tissues $(p<0.05)$. There was no significant

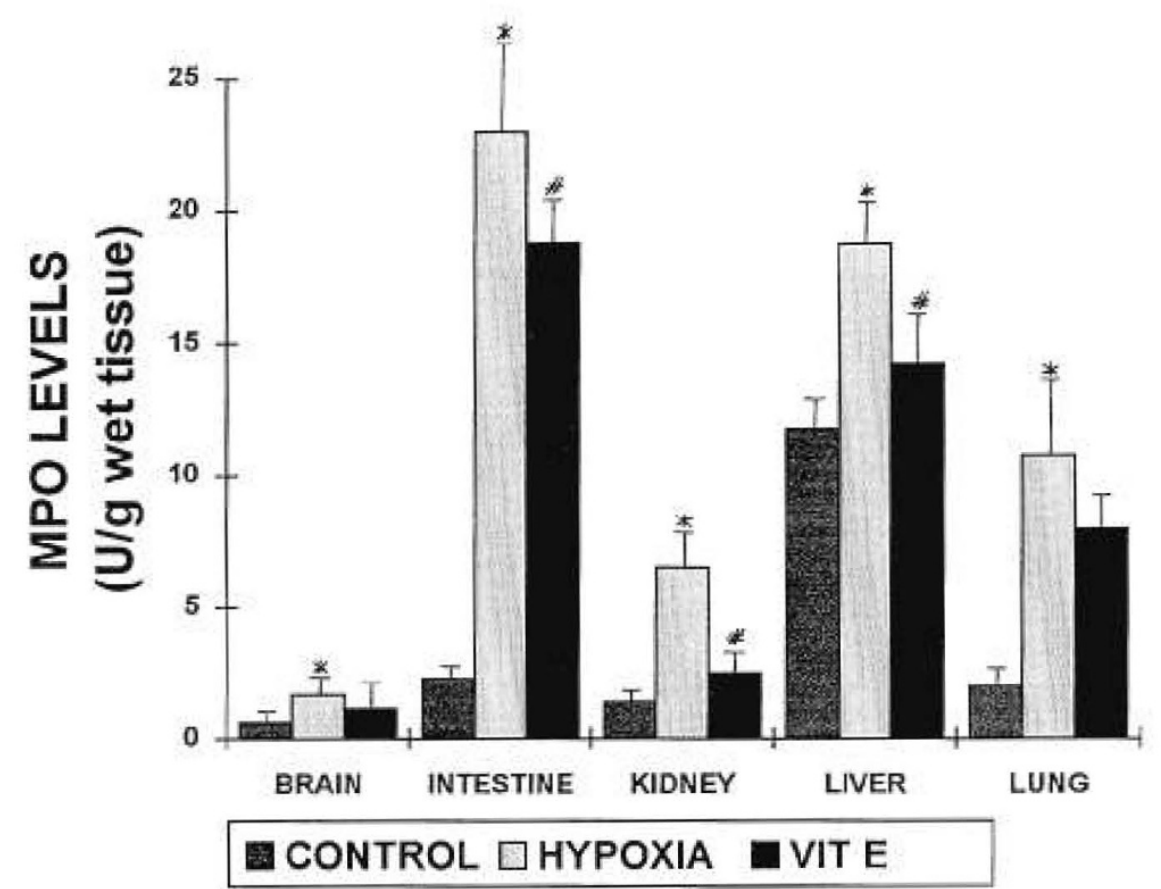

Figure 2. Tissue-associated MPO activity in newborn rats. Values are means \pm 1 SD. ${ }^{*} p<0.05$ for MPO activity compared with control group, and \#p<0.05 for the effect of vitamin $\mathrm{E}$ compared with hypoxic group. 
difference between the control group and the vitamin E group, showing that the drug completely abated the rise in lipid peroxidation in these tissues $(p>0.05)$. In brain tissue, MDA levels were significantly lower in the vitamin $\mathrm{E}$ group $(186.4 \pm$ $15.8)$ compared with the hypoxic group $(208.0 \pm 10.2)(p<$ $0.05)$. The difference between the vitamin $\mathrm{E}$ group and the control group $(141.1 \pm 12.7)$ was still significant $(p<0.05)$, showing that the brain tissue is only partially protected by vitamin E.

Mean MDA levels in the kidneys were $134.0 \pm 10.4,254.0$ \pm 28.1 , and $212.5 \pm 36.2$ for control, hypoxic, and vitamin $\mathrm{E}$ groups, respectively. Hypoxia caused an increase in lipid peroxidation in the kidneys $(p<0.05)$. However, unlike the liver and brain tissues, protection of the kidneys against oxidative injury by vitamin $\mathrm{E}$ was not statistically significant $(p>0.05)$. In our study we did not observe any effect of hypoxia and vitamin $\mathrm{E}$ on the lipid peroxidation in the lungs (Fig. 1).

Based on the measurement of MPO activity, hypoxia stimulated leukocyte infiltration into the tissues. Tissue-associated MPO activity was decreased in the vitamin E group compared with the hypoxic group, both in the liver (14.24 \pm 1.84 versus $18.74 \pm 1.58 \mathrm{U} / \mathrm{g}$ of wet tissue) and in the intestines (18.75 \pm 1.58 versus $22.94 \pm 3.34$ ) ( $p<0.05$ for both). In the control group, MPO activity was $11.77 \pm 1.12$ in the liver and $2.27 \pm$ 0.43 in the intestines. Both control values were significantly lower than the vitamin $\mathrm{E}$ group $(p<0.05$ ), implying that vitamin $\mathrm{E}$ only partially can inhibit hypoxia-induced leukocyte infiltration. Similar results were obtained for the kidneys. Compared with the control $(1.40 \pm 0.41)$, MPO activity was significantly increased in the hypoxic group $(6.50 \pm 1.41)$, and vitamin $\mathrm{E}$ decreased the kidney-associated MPO activity (2.47 $\pm 0.79)(p<0.05)$. Hypoxia increased MPO activity both in brain and lungs $(p<0.05)$; however, vitamin $\mathrm{E}$ had no significant effect the MPO activities in these tissues $(p>0.05)$ (Fig. 2).

Histopathologic results. Histopathologic studies were performed only on a limited number of animals because the tissue samples were not large enough for complete histopathologic investigation. In the hypoxic group, lungs and intestines were sampled from three rats; brains, kidneys, and livers were evaluated from two animals. In the vitamin E-treated groups, lungs and brain were sampled from each animal, whereas livers were from seven, kidneys from five, and intestines from four animals. Finally, in the control group, lungs, brains, and intestines were sampled from four animals, whereas livers from three and kidneys from two animals were analyzed.

The most striking histopathologic changes were observed in the intestines. Sections of the intestines from the hypoxic group revealed villous epithelial separation, hyperemia, and an increased number of leukocytes in the mucosa and submucosa. None of these was observed in the vitamin E-treated or control groups (Fig. 3, $a-c$ ).

In the livers of the hypoxic group, in contrast to the other two groups, extensive leukocyte infiltration was present in portal areas (Fig. 4, $a-c$ ). No histopathologic alterations were seen in the lungs, brains, and kidneys.

\section{DISCUSSION}

In this study vitamin $\mathrm{E}$ administered antenatally to pregnant rats prevented hypoxia-induced biochemical changes in all

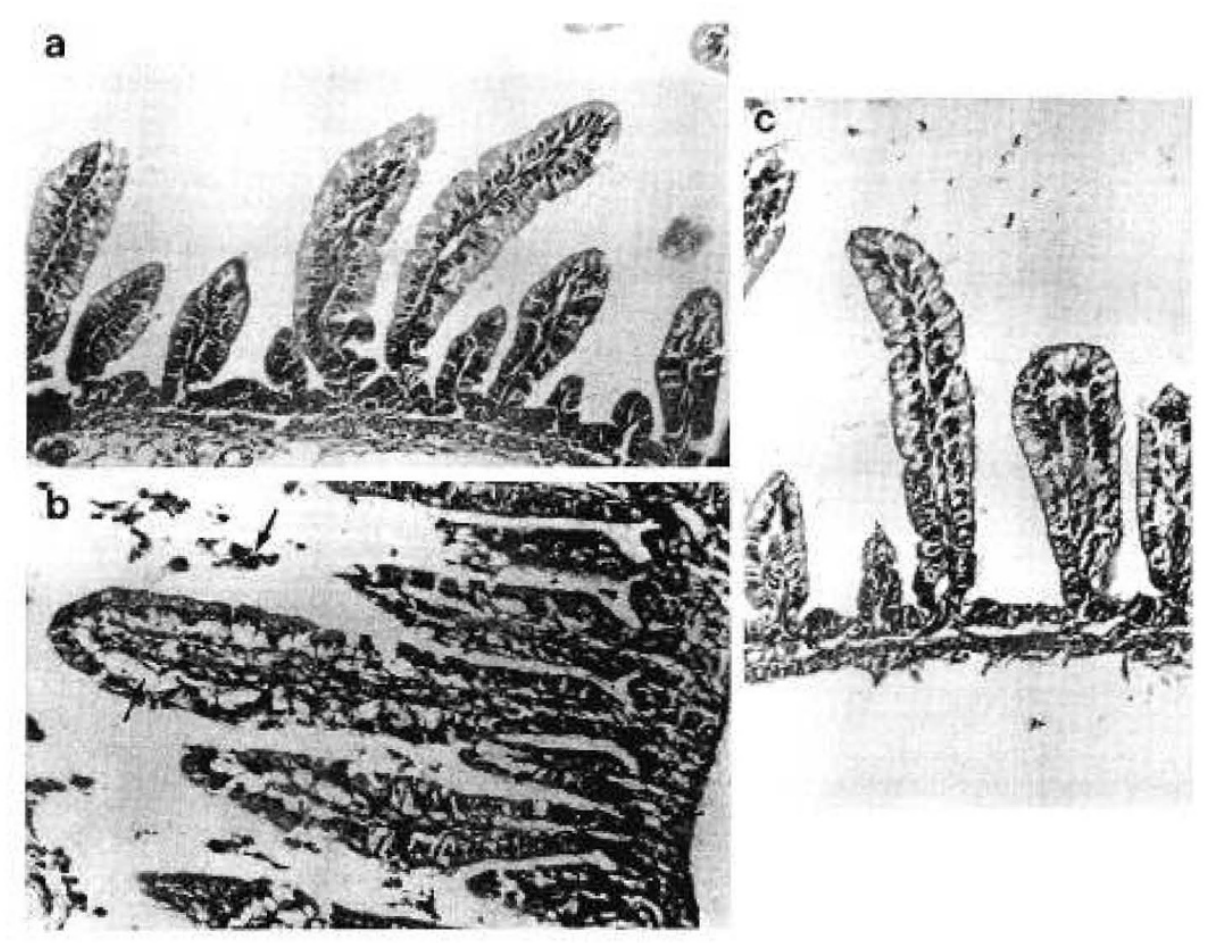

Figure 3. Light microscopic photographs of intestinal tissues. $a$, Control group; $b$, hypoxic rat intestine. Arrows indicate epithelial separation along the villous core. Desquamated epithelial cells freely in the lumen and inflammatory cell infiltration in mucosa and submucosa. $c$, Hypoxic group receiving vitamin E antenatally. $H \& E$, original magnification, $\times 10$. 

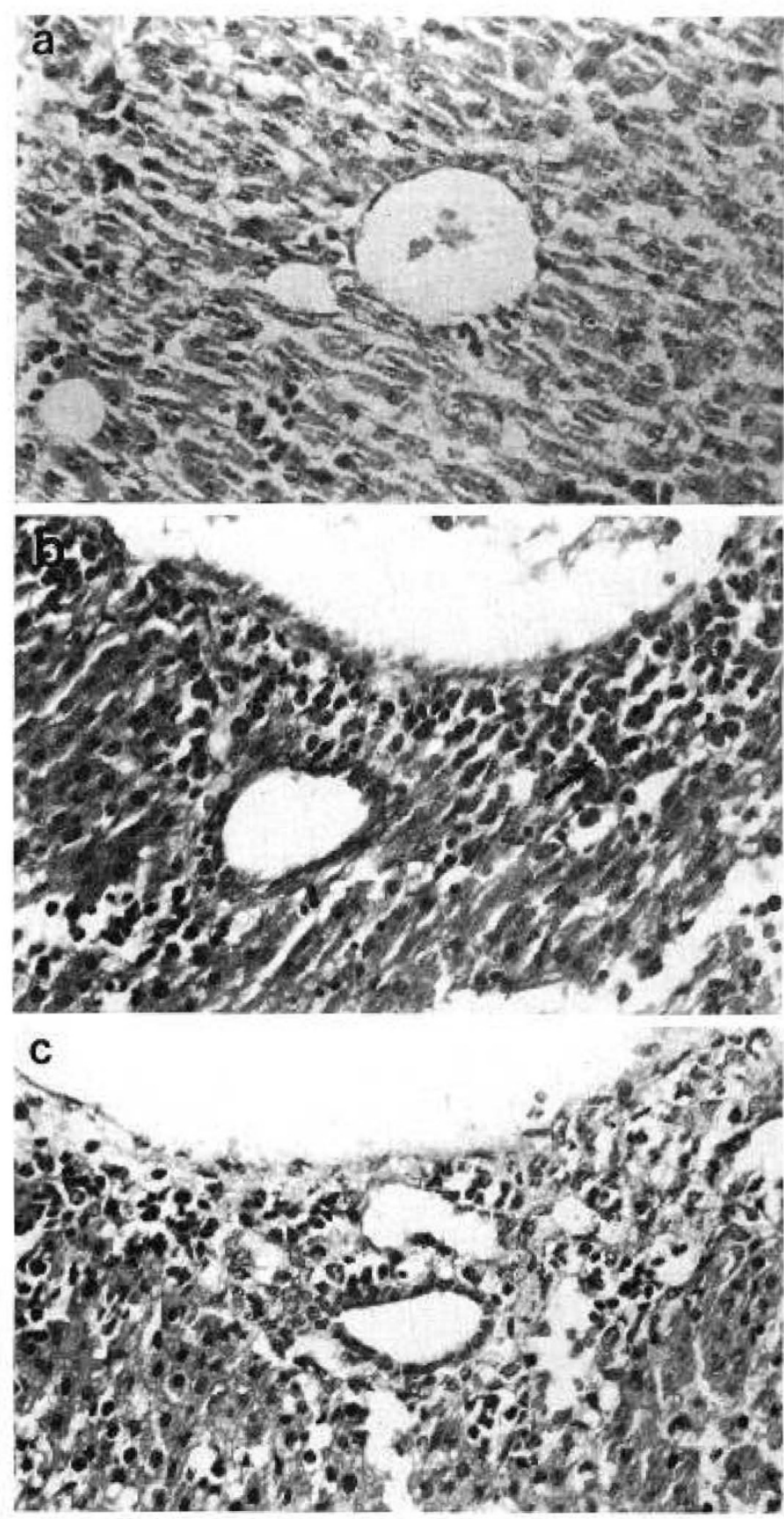

Figure 4. Light microscopic photographs of liver tissues. $a$, Control group; $b$, hypoxic group. Arrow indicates leukocyte infiltration near portal area. $c$, The vitamin $\mathrm{E}$ group. $\mathrm{H} \& \mathrm{E}$, original magnification, $\times 40$.

organs, except the lungs, and provided histopathologic protection in the liver and intestines.

Free oxygen radicals are known to be involved in cellular damage. They contribute to various organ injury at the stages of initiation and/or progression (2). Organ dysfunction induced by free radicals may be a major component of hypoxicischemic disease of the heart, intestines, liver, kidney, and brain $(2-4,18)$. The newborn baby, particularly preterm, is more vulnerable to free radical injury (4).

In our study, vitamin $\mathrm{E}$ was chosen as a scavenger of the hydroxyl radical and lipid radicals because it is the most important physiologic antioxidant that protects membrane lip- ids against oxidative damage, peroxidation (5, 7-9). Additionally, it decreases polymorphonuclear leukocyte activation, random migration, and chemotaxis and inhibits the function of leukocytes in a dose dependent manner (19-21).

Recently, the protective effect of vitamin $\mathrm{E}$ against intracranial hemorrhage was reported in premature babies who received vitamin $\mathrm{E}$ during the first few days of life (11-13). This effect possibly was achieved by stabilization of the capillary endothelial membranes $(11,12)$. Vitamin $\mathrm{E}$ apparently captures the free oxygen radicals formed in the brain after ischemia and reperfusion, thereby limiting the destruction in the subependymal areas. Similar effects have been shown in retinopathy of prematurity and bronchopulmonary dysplasia $(22,23)$. However, the protective effect of vitamin $\mathrm{E}$ in above mentioned disorders is still debated (24-29). In this study, we used thiobarbituric acid method for determination of lipid peroxidation. Although the thiobarbituric acid assay is not specific for MDA, measurement of TBARS is an easy and reliable method which is used as an indicator of lipid peroxidation and free radical activity in biologic samples. Tissue levels of MDA and the activity of MPO were used as indices of hypoxia-induced biochemical changes, because it is known that there are strong correlations between MPO activity and lipid peroxidations (30).

Compared with the control group, either MPO activity and/or MDA levels were higher in the hypoxic group in all organs except lungs. This showed that hypoxia was successfully performed.

The highest MDA levels were measured in the liver and intestines. This may be due to the fact that these organs are very rich in proteolytic enzymes, and that xanthine oxidase is more abundant in these tissues (4). Histopathologic examinations revealed the presence of leukocyte infiltration into the liver and intestines of the hypoxic group, but not that of the vitamin $\mathrm{E}$ and control groups. Because of the increased capillary permeability and chemotaxis, leukocyte infiltration is a sign of tissue damage after commencement of the hypoxic insult $(31,32)$. Inasmuch as activated leukocytes produce oxygen-derived free radicals and are the source of toxic proteases, tissue-associated MPO activity can be regarded as a marker of reoxygenation injury $(30,33)$.

Hypoxia induced neither lipid peroxidation nor histopathologic changes in the lungs. It is known that lung microsomes are much more resistant to peroxidation in vitro than those of other organs, such as liver and kidneys. The ratio of vitamin $\mathrm{E}$ to peroxidizable lipids is six times higher in lungs than in liver or kidneys (34). There relatively high amounts of vitamin E might protect membrane lipids from peroxidation. Compared with the other organs, the brain may be especially vulnerable to oxy-radical induced injury because of the high rate of oxidative activity, high concentration of polyunsaturated fatty acids and the low levels of antioxidant enzymes, such as catalase and glutathione peroxidase (18).

In our study, vitamin $\mathrm{E}$ partially inhibited hypoxia-induced lipid peroxidation in the brain. We did not detect any histopathologic changes in this tissue. This may be explained by the fact that a dual insult of both hypoxia and ischemia is necessary to cause histopathologic injury of brain $(14,18,35)$. 
In the kidneys, hypoxia caused elevations in both lipid peroxidation and MPO activity. Vitamin E only partially inhibited the rise in MPO, and it had no significant effect on the MDA levels.

It is known that the vitamin E level is decreased in hypoxemia, ischemia, and during postischemic recirculation (6). It is low in preterm and low birth weight infants. Nearly $25 \%$ of antenatally administered vitamin E crosses the placenta and the plasma and cord levels correlates with that in the maternal circulation (36-39).

Administration in repetitive doses increases plasma vitamin E levels. After i.v. administration, serum concentrations of vitamin $\mathrm{E}$ begin to fall by $24 \mathrm{~h}$. Whereas tissue concentrations decrease after $3 \mathrm{~d}$ (40). Therefore, to increase and keep the maternal and consequently fetal serum concentrations at a steady level, a high dose vitamin $\mathrm{E}$ was given on 3 consecutive days. We wanted to investigate the possible protective effect of antenatal vitamin $\mathrm{E}$ because hypoxic injury in the newborn most commonly occurs in the antenatal and intrapartum period (1). Therefore, prophylactic drugs and interventions to prevent the devastating consequences of this condition seem more crucial. In this study, mammary transfer had no contribution to the protective effect of vitamin $\mathrm{E}$ as the rat pups were not nursed during the entire study period. It is known that mammary transfer of vitamin $\mathrm{E}$ is quite sufficient (41).

Because tissue levels of vitamin $\mathrm{E}$ were not measured, it is not possible to derive a definite conclusion concerning the rate and amount of vitamin $\mathrm{E}$ transfer across the placenta. We did not observe any teratogenic effect or premature labor, intrauterine fetal death, or any other adverse effects, such as necrotizing enterocolitis, presumed to be associated with a high dose of vitamin $\mathrm{E}(42,43)$.

The data obtained in this study strongly suggest that vitamin E can have prophylactic efficacy against hypoxia/reoxygenation-induced tissue injury. Further clinical studies are necessary to investigate the potential role of antenatal vitamin $\mathrm{E}$ in preventing hypoxic-ischemic injury in the newborn.

Acknowledgments. The authors express their gratitude to Prof. Dr. W. E. Criss from the Department of Biochemistry, Hacettepe University, for carefully reading this manuscript and to Associate Prof. Dr. Turgay Coşkun from the Department of Pediatrics, Hacettepe University, for his continuous support in this study.

\section{REFERENCES}

1. Pasternak JF 1993 Hypoxic-ischemic brain damage in the term infant. Pediatric Clin North Am 40:1061-1072

2. McCord JM 1985 Oxygen derived free radicals in postischemic tissue injury. N Engl J Med 312:159-163

3. Werns SW, Lucchesi BR 1990 Free radicals and ischemic tissue injury. Trends Pharmacol Sci 16:161-166

4. Saugstad OD 1988 Hypoxanthine as an indicator of hypoxia:Its role in health and disease through free radical production. Pediatr Res 23:143-150

5. Mascio PD, Murphy ME, Sies H 1991 Antioxidant defense systems:the role of carotenoids, tocopherols, and thiols. Am J Clin Nutr 53:194S-200S

6. Majewska MD, Strosznajder J, Lazerewicz J 1978 Effect of ischemic anoxia and barbiturate anesthesia on free radical oxidation of mitochondrial phospholipids. Brain Res 158:423-434
7. Burton GW, Ingold KU 1989 Vitamin $\mathrm{E}$ as an in vitro and in vivo antioxidant. Ann NY Acad Sci 570:7-21

8. Niki E, Yamamoto Y, Takahashi M, Komura E, Miyama Y 1989 Inhibition of oxidation of biomembranes by tocopherol. Ann NY Acad Sci 570:23-31

9. Urano S, Matsuo M 1989 Membrane-stabilizing effect of vitamin E. Ann NY Acad Sci 570:524-526

10. Chiswick M, Gladman G, Sinha S, Toner N, Davies J. 1989 Prophylaxis of periventricular hemorrhage in preterm babies by vitamin E supplementation. Ann NY Acad Sci 570:197-204

11. Chiswick M, Gladman G, Sinha S, Toner N, Davies J 1991 Vitamin E supplementation and periventricular hemorrhage in the newborn. Am J Clin Nutr 53.370S-372S

12. Fish WH, Cohen M, Franzek D, Williams JM, Lemons JA 1990 The effect of intramuscular vitamin $\mathrm{E}$ on mortality and intracranial hemorrhage in neonates of 1000 grams or less. Pediatrics 85:578-584

13. Poland RL 1990 Vitamin E for prevention of perinatal intracranial hemorrhage. Pediatrics 85:865-867

14. Vannucci RC, Christensen MA, Yager JY 1993 Nature, Time-course and extent of cerebral edema in perinatal hypoxic-ischemic brain damage. Pediatr Neurol 9:29-34

15. Hansbrough F, Priebe CJ, Falterman KW, Bornside GH, Welsh RA 1983 Pathogenesis of early necrotizing enterocolitis in the hypoxic neonatal dog. Am J Surg 145:169-176

16. Uchiyama M, Mihara S 1978 Determination of malonaldehyde precursor in tissues by thiobarbituric acid test. Anal Biochem 86:271-275

17. Grisham MB, Hernandez LA, Granger DN 1986 Xanthine oxidase and neutrophil infiltration in intestine ischemia. Am J Physiol 251:G567-G574

18. Vannucci RC 1990 Experimental biology of cerebral hypoxia-ischemia: relation to perinatal brain damage. Pediatr Res 27:317-326

19. Goetzl EJ 1980 Vitamin E modulates the lipoxygenation of arachidonic acid in leukocytes. Nature 288:183-185

20. Engle WA, Yoder MC, Baurley JL, Yu P 1988 Vitamin E decreases superoxide anion production by polymorphonuclear leukocytes. Pediatr Res 23:245-248

21. Prasad JS 1980 Effect of vitamin E supplementation on leukocyte function. Am J Clin Nutr 33:606-608

22. Hittner HM 1989 Discussion. Ann NY Acad Sci 570:205-207

23. Phelps DL 1988 The role of vitamin E therapy in high-risk neonates. Clin Perinatol 15:955-963

24. Phelps DL, Rosenbaum AL, Isenberg SJ, Leake RD, Dorey F 1987 Tocopherol efficacy and safety for preventing retinopathy of prematurity: randomized, controlled and double-masked trial. Pediatrics 79:489-500

25. Puklin JE, Simon RM, Ehrenkranz RA 1982 Influence on retrolental fibroplasia of vitamin $E$ administration during respiratory distress syndrome. Ophthalmology 89:96-103

26. Ehrenkranz RA, Ablow RC, Warshaw JB 1979 Prevention of bronchopulmonary dysplasia with vitamin $\mathrm{E}$ administration during the acute stages of respiratory distress syndrome. J Pediatr 95:873-878

27. Soldanha RL, Cepeda EE, Poland RL 1982 The effect of vitamin E prophylaxis on the incidence and severity of bronchopulmonary dysplasia. J Pediatr 101:89-93

28. Gole GA, Skinner JM, Henderson DW, Mukherjee TM 1984 Vitamin E effect questioned. Pediatrics 73:734

29. Gorodischer R 1990, Micronutrients and drug response: vitamin A and vitamin E in the fetus and in the newborn. Dev Pharmacol Ther 15:166-172

30. Otamiri T, Lindahi M, Tagesson C 1988 Phospholipase $A_{2}$ inhibition prevents mucosal damage associated with small intestinal ischemia in rats. Gut 29:489-494

31. Barlow B, Santulli TV 1975 Importance of multiple episodes of hypoxia or cold stress on the development of enterocolitis in an animal model. Surgery 77:687-690

32. Haglund U, Bulkley GB, Granger DN 1987 On the pathophysiology of intestinal ischemic injury. Acta Chir Scand 153:321-324

33. Pincemail J, Faymonville ML, Dupont GD, Thirion A, Deby C, Lamy M 1989 Neutrophil activation evidenced by plasmatic myeloperoxidase release during cardiopulmonary bypass in humans. Ann NY Acad Sci 570:501-503

34. Dilley ED, Jenkinson SG, Lawrence RA 1989 Effects of hyperoxia and vitamin E on the fatty acid composition of rat lung microsomes and mitochondria. Am Rev Respir Dis 140:423-429

35. Levine S 1960 Anoxic ischemic encephalopathy in rats. Am J Pathol 36:1-12

36. Baker H, Frank O, Thomson AD, Langer A, Munves ED, Angelis BD, Kaminetzky HA 1975 Vitamin profile of 174 mothers and newborns at parturition. Am J Clin Nutr 28:59-65

37. Leonard PJ, Doyle E, Harrington W 1972 Levels of vitamin E in the plasma of newborn infant and of the mothers. Am J Clin Nutr 25:480-484

38. Martinez FE, Goncalves AL, Jorge SM, Desai ID 1981 Vitamin E in placental blood and its interrelationship to maternal and newborn levels of vitamin E. J Pediatr 99:298-300

39. Hågå P, Ek J, Kran S 1982 Plasma tocopherol levels and vitamin E/ $\beta$-lipoprotein relationships during pregnancy and in cord blood. Am J Clin Nutr 36:1200-1204

40. Knight ME, Roberts RJ 1986 Disposition of intravenously administered pharmacologic doses of vitamin $\mathrm{E}$ in newborn rabbits. J Pediatr 108:145-150

41. Martin MM, Hurley LS 1977 Effect of large amounts of vitamin E during pregnancy and lactation. Am J Clin Nutr 30:1629-1637

42. Hook EB, Healy KM, Niles AM, Skalko RG 1974 Vitamin E: teratogen or antiteretogen? Lancet 27:809

43. Finer NN, Peters KL, Hayek Z, Merkel CL 1984 Vitamin E and necrotizing enterocolitis. Pediatrics 73:387-393 